\title{
Anti-melanogenic Fatty Acid Derivatives from the Tuber-barks of Colocasia antiquorum var. esculenta
}

\author{
Ki Hyun Kim, Eunjung Moon, ${ }^{\dagger}$ Sun Yeou Kim, ${ }^{\dagger}$ and Kang Ro Lee* \\ Natural Products Laboratory, School of Pharmacy, Sungkyunkwan University, Suwon 440-746, Korea \\ *E-mail: krlee@skku.ac.kr \\ ${ }^{\dagger}$ East-West Medical Science Integrated Research Center, Graduate School of East-West Medical Science, \\ Kyung Hee University, Yongin 449-701, Korea \\ Received April 6, 2010, Accepted May 4, 2010
}

Key Words: Colocasia antiquorum var. esculenta, Araceae, Monoglyceride, Melan-a cells, Anti-melanogenic activity

As part of our continuing search for biologically active compounds from natural medicinal plant sources, ${ }^{1-3}$ we investigated the anti-melanogenic constituents from thetuber-barks of Colocasia antiquorum var. esculenta, since the methanolic extract of tuber-barks of C. antiquorum var. esculenta showed inhibitory effects on melanin production in melan-a cells. C. antiquorum var. esculenta (Araceae) is widely spread in Korea, and is a variant of $C$. antiquorum, commonly known as 'Imperial Taro', exhibiting antifungal activity. ${ }^{4}$ We have recently reported the lignan derivatives with anti-melanogenic activity from this source. ${ }^{5}$ In a continuing study on this source, we have further isolated a new monoglyceride, $(2 ' S)-1-O-(9-$ oxo-10(E), 12(E)octadecadienoyl) glycerol (1) (Figure 1), as well as nine fatty acid derivatives (2-10) from the EtOAc soluble fraction of its

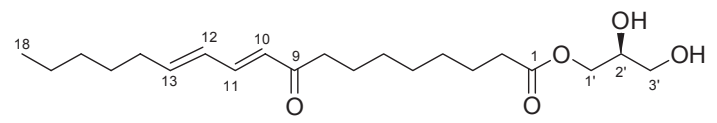

Figure 1. Chemical structure of $\mathbf{1}$.

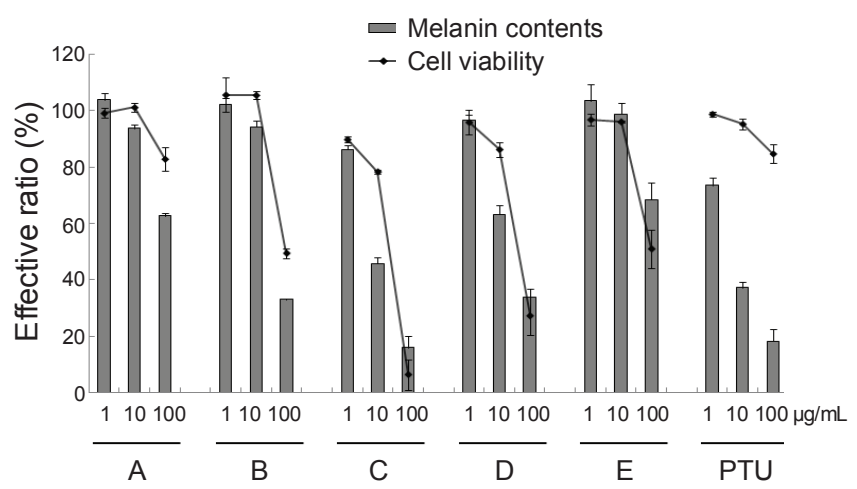

Figure 2. The effect of fractions A, B, C, D and E from the EtOAC soluble fraction of the methanolic extract of tuber-barks of $C$. antiquorum var. esculenta on melanogenesis in melan-a cells. Test samples were tested at three concentrations of 1,10 and $100 \mu \mathrm{g} / \mathrm{mL}$. PTU (1-phenyl-2-thiourea) was used as positive control. Test sample and medium were renewed daily. The cell viabilities and the melanin contents of melan-a cells were determined after 3 days. Inhibitory activity of melanogenesis and the effect of cell viability were expressed as a percentage of the control. The data shown represent the means \pm SD of three independent experiments performed in duplicate.
$\mathrm{MeOH}$ extract using a bioassay-guided column chromatographic separation (Figure 2). Here, we describe the isolation and structural elucidation of $\mathbf{1}$ as well as the anti-melanogenic activities of the isolated compounds (1-10).

Compound 1 was obtained as an amorphous gum with optical rotation $[\alpha]_{\mathrm{D}}^{25}+4.28^{\circ}(c 0.12, \mathrm{MeOH})$. The molecular formula was determined to be $\mathrm{C}_{21} \mathrm{H}_{36} \mathrm{O}_{5}$ by HREIMS: observed, 368.2549 (calcd. for $\mathrm{C}_{21} \mathrm{H}_{36} \mathrm{O}_{5}, 368.2563$ ). The ${ }^{1} \mathrm{H}$ NMR spectrum of 1 displayed signals for the presence of two conjugated $E, E$-form enone system at $\delta 7.24(\mathrm{dd}, J=11.5,15.5 \mathrm{~Hz}), 6.28(\mathrm{dd}, J=$ $11.5,15.0 \mathrm{~Hz}), 6.27$ (dd, $J=5.5,15.0 \mathrm{~Hz}$ ), and 6.13 (d, $J=$ $15.5 \mathrm{~Hz}$ ). Furthermore, the UV spectrum of 1 displayed a $\lambda_{\max }$ at $276 \mathrm{~nm}$. The ${ }^{1} \mathrm{H}$ NMR spectrum also showed a triplet peak at $\delta 0.92(\mathrm{H}-18)$, a multiplet signal at $\delta 1.32-1.35(\mathrm{H}-4,5,6$, $16,17)$, and two triplets at $\delta 2.36(\mathrm{H}-2)$ and $2.60(\mathrm{H}-8)$. The ${ }^{13} \mathrm{C}$ NMR spectrum (including DEPT and HMQC) exhibited 21 carbon signals, including two carbonyl carbons at $\delta 202.7$ (C-9) and $174.3(\mathrm{C}-1)$, four olefinic carbons at $\delta 146.2$ (C-13), 144.1 (C-11), 129.0 (C-12), and 127.6 (C-10). The NMR spectral data of 1 were very similar to those of 9-oxo-10(E),12(E)-octadecadienoic acid. ${ }^{6}$ Besides, an additional presence of a glycerol moiety $\left[\delta_{\mathrm{H}} 4.16(1 \mathrm{H}, \mathrm{dd}, J=11.6,4.6 \mathrm{~Hz}), 4.08(1 \mathrm{H}, \mathrm{dd}, J=11.6\right.$, $6.3 \mathrm{~Hz}), 3.82(1 \mathrm{H}, \mathrm{m}), 3.57(1 \mathrm{H}, \mathrm{dd}, J=11.3,5.3 \mathrm{~Hz}), 3.55$ $(1 \mathrm{H}, \mathrm{dd}, J=11.3,5.7 \mathrm{~Hz}) ; \delta_{\mathrm{C}} 70.0\left(\mathrm{C}-2^{\prime}\right), 65.3$ (C-1'), 62.9 (C-3')] was observed. ${ }^{7}$ The connectivity of 1 was confirmed by the HMBC spectrum, in which cross-peaks between $\mathrm{H}-1^{\prime} / \mathrm{C}-1$, H-7/C-9, H-11/C-9, H-15/C-13, and H-18/C-16 were observed (Figure 3). The position of the dienone moiety was further confirmed by analysis of the mass fragmentation in the HREIMS data (Figure 3). Based on these data, the planar structure of $\mathbf{1}$

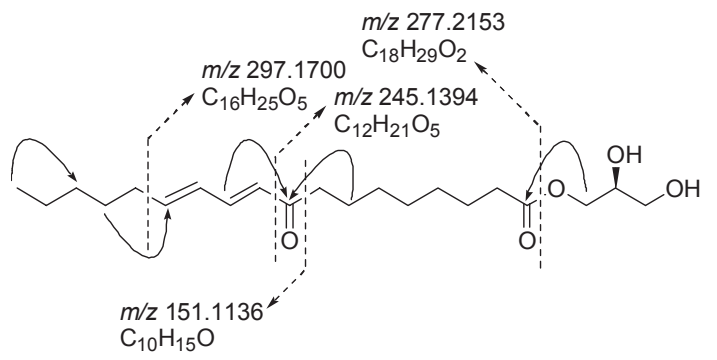

Figure 3. Key HMBC connectivities and HREIMS fragmentation of $\mathbf{1}$. 


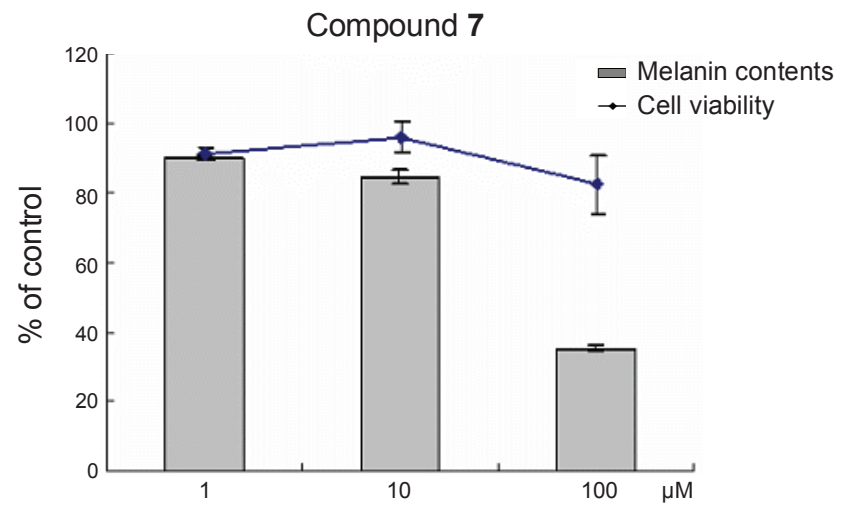

Figure 4. The effect of compound 7 on melanogenesis in melan-a cells. Compound 7 was tested at three concentrations of 1,10 and $100 \mu \mathrm{M}$. Compound 7 and medium were renewed daily. The cell viabilities and the melanin contents of melan-a cells were determined after 3 days. Inhibitory activity of melanogenesis and the effect of cell viability were expressed as a percentage of the control. The data shown represent the means \pm SD of three independent experiments performed in duplicate.

was determined to be 1-O-(9-oxo-10,12-octadecadienoyl) glycerol. The stereochemistries at $\mathrm{C}-10 / 11$ and $\mathrm{C}-12 / 13$ were determined to be $10(E)$ and $12(E)$, respectively, on the basis of the $J$ value and comparison of chemical shift pattern at olefinic protons of related unsaturated fatty acids. ${ }^{6,8}$ The absolute configuration at C-2' was determined using a dibenzoate chirality method. ${ }^{9}$ The hydroxyl groups at C-2' and C-3' of $\mathbf{1}$ were esterified with benzoyl chloride in dry pyridine to obtain 1a. The CD spectrum of 1a exhibited a positive exciton couplet CD peak at $235 \mathrm{~nm}$ to reflect its 2 'S configuration. ${ }^{9}$ The optical rotation value of $1\left([\alpha]_{\mathrm{D}}^{25}+4.28^{\circ}\right)$ was also in agreement with that of a synthetic monoglyceride in the $S$-form. ${ }^{7}$ Thus, the structure of 1 was determined to be (2'S)-1-O-(9-oxo-10(E), $12(E)$-octadecadienoyl) glycerol. Although the free fatty acid moiety of $\mathbf{1}$ has already been reported, ${ }^{6}$ this is the first isolation of the monoglyceride (1) from natural sources.

The known compounds were identified as $(R)-(-)-9$-hydroxydecenoic acid (2), ${ }^{10,11}(R)-(-)-9$-hydroxydecanoic acid (3), ${ }^{11}$ $(2 E, 4 S)$-4-hydroxy-2-nonenoic acid $(4),{ }^{12}(S)$-15,16-didehydrocoriolic acid (5), ${ }^{13} 1-O$-(octanoyl) glycerol (6) $,{ }^{14} 12,13$-epoxyoctadec- $9(Z)$-enoic acid (7), ${ }^{15,16}(9 S, 10 E, 12 Z)$-10,12-octadecadienoic acid methyl ester $(\mathbf{8}){ }^{8}(9 S, 10 E, 12 Z)-10,12$-octadecadienoic acid (9), ${ }^{8}$ and 12,13-epoxyoctadec-6(Z), $9(Z)$-dienoic acid (10) ${ }^{17}$ respectively, by comparison of their physical, NMR and MS spectral data reported in previous literature. The compound 4, $(2 E, 4 S)$-4-hydroxy-2-nonenoic acid was isolated for the first time from natural sources, although previously synthesized. ${ }^{12}$

We evaluated the inhibitory effects of all the isolated compounds (1-10) on melanogenesis by examining their effects on melanin biosynthesis in melan-a cells. The melan-a cells were treated with various concentrations $(1,10$, or $100 \mu \mathrm{M})$ of each test compound for 3 days. Compounds 2, 3, 4 and $\mathbf{9}$ did not affect melanogenesis in melan-a cells. But, compound 7 dosedependently inhibited melanin content without significant cell toxicity. At a concentration of $100 \mu \mathrm{M}$, compound 7 strongly inhibited the melanin biosynthesis with an effective ratio of $35.43 \pm 0.79 \%$ in comparison to the control (Figure 4). Monoglyceride (6) was also active in the inhibition of melanin content at a concentration of $10 \mu \mathrm{M}$, although it exhibited cell toxicity at higher concentrations (see the Supporting Information). The compound 10, which contained an epoxy group, slightly reduced melanin contents but displayed cell toxicity at higher concentrations.

It was recently reported that 6-O-undecylenoyl $p$-hydroxyphenyl $\beta$-D-glucopyranoside, which was synthesized by transesterification of arbutin and undecylenic acid vinyl ester, more significantly suppressed melanin production in murine B16 melanoma cells than arbutin. ${ }^{18}$ Several hydroquinone fatty acid esters have been investigated for the development of better depigmenting agents than hydroquinones. ${ }^{19}$ The active fatty acids $(\mathbf{6}, 7$, and 10) isolated from this source could be used as novel tools for the synthesis of effective depigmenting agents and also as good candidates for cosmetic development.

\section{Experimental Section}

General procedures. Optical rotations were measured on a Jasco P-1020 polarimeter in MeOH. IR spectra were recorded on a Bruker IFS-66/S FT-IR spectrometer. CD spectra were measured on a Jasco J-715 spectropolarimeter. EI and HREI mass spectra were obtained on a JEOL JMS700 mass spectrometer. NMR spectra were recorded on a Varian UNITY INOVA $500 \mathrm{NMR}$ spectrometer operating at $500 \mathrm{MHz}\left({ }^{1} \mathrm{H}\right)$ and 125 $\mathrm{MHz}\left({ }^{13} \mathrm{C}\right)$, respectively. Preparative HPLC was conducted using a Gilson 306 pump with Shodex refractive index detector. Low-pressure liquid chromatography was carried out over a Merck Lichroprep Lobar-A Si $60(240 \times 10 \mathrm{~mm})$ with a FMI QSY-0 pump (ISCO). Silica gel 60 (Merck, 70 - 230 mesh and 230 - 400 mesh) and RP-C 18 silica gel (Merck, 230 - 400 mesh) were used for column chromatography (CC). Merck pre-coated Silica gel $\mathrm{F}_{254}$ plates and RP- $18 \mathrm{~F}_{254 \mathrm{~s}}$ plates were used for TLC. Spots were detected on TLC under UV light or by heating after spraying with $10 \% \mathrm{H}_{2} \mathrm{SO}_{4}$ in $\mathrm{C}_{2} \mathrm{H}_{5} \mathrm{OH}$ ( $\mathrm{vol} / \mathrm{vol}$ ).

Plant materials. The tuber-barks of C. antiquorum var. esculenta were collected at Girokdo, Goksung of Jeonnam province, Korea, in November 2006. Samples of plant material were identified by one of the authors (K. R. Lee). A voucher specimen (SKKU 2006-11) was deposited in the herbarium of the School of Pharmacy, Sungkyunkwan University, Suwon, Korea.

Extraction and isolation. The dried tuber-barks of C. antiquorum var. esculenta $(3.8 \mathrm{~kg}$ ) were extracted with $85 \% \mathrm{MeOH}$ using an ultrasonic apparatus for $1 \mathrm{~h}$. The resultant methanolic extract $(350 \mathrm{~g})$ was suspended in distilled water $(15 \mathrm{~L})$ and then successively partitioned with EtOAc to give an EtOAc extract (36 g). The EtOAc soluble fraction ( $36 \mathrm{~g}$ ) was chromatographed on an RP- $\mathrm{C}_{18}$ silica gel (230 - 400 mesh, $500 \mathrm{~g}$ ), eluting with gradient solvent system of $\mathrm{MeOH} / \mathrm{H}_{2} \mathrm{O}$ (3:2 and 1:0, vol/ $\mathrm{vol}, 500 \mathrm{~mL}$ each). According to TLC analysis, five crude fractions (fr. A - E) were collected. All fractions were evaluated on anti-melanogenic activities in melan-a cells (Figure 2). Fr. C $(3 \mathrm{~g})$, which showed the most significant inhibitory activity among the five fractions tested, was applied to CC on a silica 
Table 1. ${ }^{1} \mathrm{H}$ and ${ }^{13} \mathrm{C}$ NMR data of $\mathbf{1}\left(\delta\right.$ in ppm, $500 \mathrm{MHz}$ for ${ }^{1} \mathrm{H}$ and $125 \mathrm{MHz}$ for ${ }^{13} \mathrm{C}$, in $\mathrm{CD}_{3} \mathrm{OD}$ )

\begin{tabular}{|c|c|c|c|c|}
\hline \multirow{2}{*}{ Atom no. } & \multicolumn{3}{|c|}{${ }^{1} \mathrm{H}$ NMR } & \multirow{2}{*}{$\frac{{ }^{13} \mathrm{C} \text { NMR }}{\delta \text { (DEPT) }}$} \\
\hline & $\delta$ & $\mathrm{m}$ & $J(\mathrm{~Hz})$ & \\
\hline 1 & & & & $174.3(\mathrm{C})$ \\
\hline 2 & 2.36 & $\mathrm{t}$ & 7.0 & $33.7\left(\mathrm{CH}_{2}\right)$ \\
\hline 3 & 1.62 & $\mathrm{~m}$ & & $24.7\left(\mathrm{CH}_{2}\right)$ \\
\hline 4 & $1.32-1.35$ & $\mathrm{~m}$ & & $28.8^{a}\left(\mathrm{CH}_{2}\right)$ \\
\hline 5 & $1.32-1.35$ & $\mathrm{~m}$ & & $28.8^{a}\left(\mathrm{CH}_{2}\right)$ \\
\hline 6 & $1.32-1.35$ & $\mathrm{~m}$ & & $28.9^{a}\left(\mathrm{CH}_{2}\right)$ \\
\hline 7 & 1.62 & $\mathrm{~m}$ & & $24.3\left(\mathrm{CH}_{2}\right)$ \\
\hline 8 & 2.60 & $\mathrm{t}$ & 7.5 & $39.8\left(\mathrm{CH}_{2}\right)$ \\
\hline 9 & & & & 202.7 (C) \\
\hline 10 & 6.13 & $\mathrm{~d}$ & 15.5 & $127.6(\mathrm{CH})$ \\
\hline 11 & 7.24 & dd & $11.5,15.5$ & $144.1(\mathrm{CH})$ \\
\hline 12 & 6.28 & dd & $11.5, .15 .0$ & $129.0(\mathrm{CH})$ \\
\hline 13 & 6.27 & dd & $5.5,15.0$ & $146.2(\mathrm{CH})$ \\
\hline 14 & 2.21 & $\mathrm{~m}$ & & $32.9\left(\mathrm{CH}_{2}\right)$ \\
\hline 15 & 1.46 & $\mathrm{~m}$ & & $28.3\left(\mathrm{CH}_{2}\right)$ \\
\hline 16 & $1.32-1.35$ & $\mathrm{~m}$ & & $31.3\left(\mathrm{CH}_{2}\right)$ \\
\hline 17 & $1.32-1.35$ & $\mathrm{~m}$ & & $22.3\left(\mathrm{CH}_{2}\right)$ \\
\hline 18 & 0.92 & $\mathrm{t}$ & 7.0 & $13.1\left(\mathrm{CH}_{3}\right)$ \\
\hline $1^{\prime}$ & $\begin{array}{l}4.16 \\
4.08\end{array}$ & $\begin{array}{l}\mathrm{dd} \\
\mathrm{dd}\end{array}$ & $\begin{array}{l}4.6,11.6 \\
6.3,11.6\end{array}$ & $65.3\left(\mathrm{CH}_{2}\right)$ \\
\hline $2^{\prime}$ & 3.82 & $\mathrm{~m}$ & & $70.0(\mathrm{CH})$ \\
\hline \multirow{2}{*}{$3^{\prime}$} & 3.57 & dd & $5.3,11.3$ & \multirow{2}{*}{$62.9\left(\mathrm{CH}_{2}\right)$} \\
\hline & 3.55 & $\mathrm{dd}$ & $5.7,11.3$ & \\
\hline
\end{tabular}

${ }^{a}$ Interchangeable signals.

gel (230 - 400 mesh, $80 \mathrm{~g})$, eluting with solvent system of $\mathrm{CHCl}_{3} / \mathrm{MeOH}(10: 1$, vol/vol, $500 \mathrm{~mL})$ to give three subfractions (fr. C1 - C3). Among three subfractions, fr. C2 (1.3 g), which showed the most significant inhibitory activity, was applied to CC on an RP-C 18 silica gel (230 - 400 mesh, $50 \mathrm{~g})$, eluting with solvent system of $\mathrm{MeOH} / \mathrm{H}_{2} \mathrm{O}$ (4:1, vol/vol, 500 $\mathrm{mL}$ ) to afford five subfractions (fr. C21 - C25). Fr. C23 (200 $\mathrm{mg}$ ) was further purified by LPLC on Lichroprep Lobar-A Si 60 column $(5 \mathrm{~mL} / \mathrm{min}$; eluted with $n$-hexane/EtOAc, $1: 1$, vol/ vol), and preparative reversed-phase HPLC, using a solvent system of $63 \% \mathrm{MeCN}$ over $30 \mathrm{~min}$ at a flow rate of $2.0 \mathrm{~mL} / \mathrm{min}$ (Econosil RP-18 $10 \mu \mathrm{m}$ column; $250 \times 10 \mathrm{~mm}$; Shodex refractive index detector), to yield compound $\mathbf{1}(5 \mathrm{mg})$. Purification of the known compounds (2-10) was described in the Supporting Information.

(2'S)-1-O-(9-Oxo-10(E),12(E)-octadecadienoyl) glycerol (1). Amorphous gum, $[\alpha]_{\mathrm{D}}^{25}+4.28^{\circ}(c 0.12, \mathrm{MeOH})$ IR $(\mathrm{KBr})$ $v_{\max } 3382,2950,1658,1414 \mathrm{~cm}^{-1}$; UV $(\mathrm{MeOH}) \lambda_{\max }(\log \varepsilon)$, 276 (1.30); ${ }^{1} \mathrm{H}$ and ${ }^{13} \mathrm{C}$ NMR data see Table 1; EIMS $m / z 368$ $[\mathrm{M}]^{+}$; HREIMS $m / z$ (rel. int. \%) $368.2549[\mathrm{M}]^{+}\left(9, \mathrm{C}_{21} \mathrm{H}_{36} \mathrm{O}_{5}\right.$, calcd. for 368.2563), 297.1700 (48), 277.2153 (52), 245.1394 (7), 223.1547 (23), 166.7544 (56), 151.1136 (94), 95.2257 (89), $91.3241(100)$.

Synthesis of 1a (benzoyl ester of 1). To synthesize the benzoyl derivative of $\mathbf{1}$, an ice-cooled solution of $\mathbf{1}(1.0 \mathrm{mg})$ in dry pyridine $(0.75 \mathrm{~mL})$ was mixed with benzoyl chloride $(0.15 \mathrm{~mL})$, and the mixture was stirred at room temperature for $20 \mathrm{~h}$. Two drops of $\mathrm{MeOH}$ were added to the reaction mixture, stirred for $10 \mathrm{~min}$, and then diluted with EtOAc and aqueous $\mathrm{Na}_{2} \mathrm{CO}_{3}$, and the layers were separated. The organic layer was washed with brine, and the combined aqueous layer was extracted with EtOAc. The combined organic extract was dried over $\mathrm{MgSO}_{4}$ and concentrated. The residual dark-brown oil was purified by a silica gel Waters Sep-Pak Vac 6cc with $n$-hexane/EtOAc (4:1, $\mathrm{vol} / \mathrm{vol})$ to give $1 \mathrm{a}(0.5 \mathrm{mg})$ as a colorless oil (see the Supporting Information).

Biological activity. The melanin contents were measured using a modification of the methods reported by Hosoi. ${ }^{20}$ In this study, phenylthiourea (PTU) was used as the positive control. ${ }^{21}$ (see the Supporting Information).

Acknowledgments. The authors would like to thank Mr. Do Kyun Kim, Dr. Eun Jung Bang and Dr. Jung Ju Seo at the Korea Basic Science Institute for the measurements of NMR and MS spectra. This work was supported by the R \& D Institute, Miwon Commercial, Co., LTD in Korea.

Supporting Information. NMR data $\left({ }^{1} \mathrm{H}\right.$ and ${ }^{13} \mathrm{C}$ NMR) of $\mathbf{1}$, purification and chemical structures of known compounds (2-10), biological activity, and synthesis of 1a are available on request from the correspondence author.

\section{References}

1. Kim, K. H.; Ha, S. K.; Kim, S. Y.; Kim, S. H.; Lee, K. R. Bull. Korean Chem. Soc. 2009, 30, 2135.

2. Kim, K. H.; Choi, J. W.; Choi, S. U.; Seo, E.-K.; Lee, K. R. Bull. Korean Chem. Soc. 2010, 31, 1035.

3. Lee, I. K.; Kim, K. H.; Ryu, S. Y.; Choi, S. U.; Lee, K. R. Bull. Korean Chem. Soc. 2010, 31, 227.

4. Masui, H.; Kondo, T.; Kojima, M. Phytochemistry 1989, 28, 2613.

5. Kim, K. H.; Moon, E.; Kim, S. Y.; Lee, K. R. J. Agric. Food Chem. 2010, 58, 4779.

6. Hirokazu, K.; Toshiyuki, M.; Hiroko, K.; Yasushi, A.; Takahiro, I. J. Nat. Prod. 2002, 65, 1712.

7. Chang, H. W.; Jang, K. H.; Lee, D.; Kang, H. R.; Kim, T.; Lee, B. H.; Choi, B. W.; Kim, S.; Shin, J. Bioorg. Med. Chem. Lett. 2008, 18,3589 .

8. Tadahiro, K.; Toshio, N.; Rumiko, I.; Aya, K.; Tsuneo, N. Tetrahedron: Asymmetry 2001, 12, 2695.

9. Uzawa, H.; Nishida, Y.; Ohrui, H.; Meguro, H. J. Org. Chem. 1990, $55,116$.

10. Brian, M.; Allan, C. O.; Thomas, M. S. Tetrahedron 1991, 47, 1611.

11. Archana, S. P.; Sankaranarayanan, S.; Subrata, C. Tetrahedron: Asymmetry 1995, 6, 2219.

12. Pietro, A.; Mario, A.; Pierangela, C.; Anna, M. S. Tetrahedron: Asymmetry 1993, 4, 1397.

13. Yadav, J. S.; Deshpande, P. K.; Sharma, G. V. M. Tetrahedron 1992, $48,4465$.

14. Daniela, I. B.; Shuichirou, T.; Yasuo, K.; Yasuhisa, A.; Makoto, U. Tetrahedron: Asymmetry 2004, 15, 3551.

15. Tadahiro, K.; Yoshihiro, Y.; Tadao, U.; Toshiro, Y. Tetrahedron Lett. 1983, 24, 4715.

16. Falck, J. R.; Kumar, P. S.; Reddy, Y. K.; Zou, G.; Capdevila, J. H. Tetrahedron Lett. 2001, 42, 7211.

17. Gayland, F. S. Phytochemistry 1997, 16, 282.

18. Yutaka, T.; Masaru, K.; Takao, R.; Shusaku, Y.; Kenji, Y. Bioorg. Med. Chem. Lett. 2007, 17, 3105.

19. Hashimoto, A.; Hasegawa, K.; Asai, T.; Masamoto, Y.; Ichihashi, M.; Mishima, Y. J. Dermatol. 1988, 15, 37.

20. Hosoi, J.; Abe, E.; Suda, T.; Kuroki, T. Cancer Res. 1985, 45, 1474.

21. Poma, A.; Bianchini, S.; Miranda, M. Mutation Res. 1999, 446, 143. 